\title{
Teacher Role Adoption and Barriers to Participation in an Online Educational Social Network
}

\author{
Vimala Judy Kamalodeen \\ University of the West Indies, Trinidad and Tobago
}

\begin{abstract}
This study focused on how teachers participated in an educational social networking site. An online space was created to facilitate networking among teachers, sharing of best practices and to provide support to one another in an era of increasing teacher isolation and challenging work environments. This paper reports on this initiative in Trinidad and Tobago, a small island in the Caribbean, and the roles teachers adopted during participation on the site. Analysis of findings indicates that teachers preferred to participate minimally on the site and to consume content by reading rather than produce. As such their roles of participation are described as content consumers rather than content creators or producers. A number of barriers to higher participation were found and these included cultural, social, motivational, time and technological.
\end{abstract}

Keywords: educational social networking sites, online participation, barriers to online participation, roles of online participation, teacher learning, teacher participation.

\section{Introduction}

Opportunities to connect and share with others can be made possible through online learning spaces such as social networking sites (SNS) that harness the affordances of Web 2.0 tools [1][2][3]. While there has been a rapid rise in the public use of social media and social networking tools such as Facebook, Twitter and Instagram, studies do not reveal enthusiasm by teachers to use these tools with colleagues. Research on higher education institutions reveals new trends in use among faculty and students but there has not been a comparative drive to explore their use in secondary education. Online spaces allow for an inexpensive and scalable option for teacher networking [4] with added advantages of flexibility of time and space. Secondary teachers face a growing number of challenges in practice and sharing of best practices and frequent networking can enable teachers to grow professionally. Social networking sites such as Ning, elgg, Mahara and Spruz offer users a greater degree of privacy and customization to popular social networking sites and are potentially useful for educative purposes.

\section{Challenges to Teacher Networking}

The literature reveals a persistent problem of teachers' classrooms being off-limits to their colleagues and this disadvantages them from learning from one another [5][6] which denies them the opportunity to work collaboratively either through observation or research or team-teaching. This often leads to teacher isolation and a further reluctance to learn new pedagogies and approaches. Therein lies an opportunity to explore alternative ways of engaging teachers in learning with and from colleagues as they practice and to gain support from mentors and administrative and supervisory personnel. New directions in teacher learning have been suggested to meet some of the challenges that teachers currently face in professional development. A vision for professional learning initiatives that are "democratic, participatory, and inexpensive" have been proposed by Lieberman and Mace [6] which should fit in with teachers' busy schedules and provide for real-time, ongoing, workembedded support [7]. Current research on teachers' professional learning, including online environments, suggests that evaluations of outcomes be framed around "core features," including "content focus, active learning, coherence, duration, and collective participation" [8].

\subsection{Online Social Networking Sites}

Social networks and social networking sites are both found in the literature and often used interchangeably with social media. While online social network sites were initially developed to develop and sustain relationships among friends and colleagues for support, they have evolved to allow strangers to interact and establish their presence online. Facebook and LinkedIn, for example, were designed to help people expand their network of friends and can be described as Social Networking sites [3] as opposed to other types of networks which serve to maintain personal relationships. In these sites, users set up a 
profile, communicate with others on their network and share personal information about their likes, activities and history. In addition to setting up a user profile, other significant features of social networking sites that are significant, are that they provide multiple services and facilities to users through Web 2.0 tools that afford users enabled communication and collaboration. It is significant to note that these services are free [3] and require little effort.

Further research on Social networking sites reveals a useful definition by Gunawardena, Hermans, Sanchez, Richmond, Bohley and Tuttle which says that "Online spaces that can be customized to a large extent by their users, providing space for personal profiles which users complete in order to make connections with others" [9]. Social networking sites fall under the broader set of tools called Web 2.0 that has caused a shift in the ways that people today interact with each other, exchange information and share knowledge. The term 'social media' is often used to describe technologies and applications that allow social interactions among people.

\subsection{Online Participation}

Participation in online learning spaces has been receiving attention recently by researchers in an effort to comprehend what online participation really is. Online participation has been measured by the frequency of visits to the space [10] and time spent online [11]. Hrastinski draws on the work of Wenger and others and found that while participation was generally conceptualized as 'writing', there were graded levels of participation. Hrastinski puts forward a definition of online learner participation in e-learning as "a process of learning by taking part and maintaining relations with others..."[12]. The author acknowledges that participation is defined in the context of formal online courses and not informal learning environments.

\subsection{Roles of Participation and Practice}

The literature pays attention to the roles or stances that participants take in online environments and how they differ. Lave and Wenger describe participation in terms of community as the "way individuals understand, take part in and subscribe to the social norms, behaviours and values of the communities in which they participate' [13]. They may also choose not to participate (or belong to) a particular community and remain 'outsiders' or on the 'periphery'. Categories of participation are usually described in two ways, 'lurkers' and 'posters' [14]. The term 'lurkers' are used to describe silent online users and Tan cites other terms with similar notions such as 'browsers', 'read-only participants', 'non-public participants' and 'vicarious learner' [15]. The term 'posters' refers to those who "post" or "put up a message to online publics (forums, email discussion lists, etc.), which usually implies that the message is sent indiscriminately to multiple users" [15]. Research further suggests that participants play different roles over the period of the learning activity [16] and that providing opportunities for every member of the community to become a full or peripheral member is important for successful participation in that community, such as having lower entry barriers [17]. As such participation is linked to learning.

Preece and Schneiderman's Reader to Leader Model for Social Participation allows for four major roles-Reader, Contributor, Collaborator and Leader [18]. These authors suggest that while many people participate in online activities by reading, only a fraction will actually contribute by writing in textbased narratives or uploading other digital media forms or including links to other sites or pages. Other authors have used the terms content consumers and producers to describe readers and writers on social networking spaces [1][19]. Further, some contributors/ writers may become collaborators in a particular activity or group while an even smaller number may emerge as leaders who can mentor novices or maintain the environment. Teacher leadership has been emerging in importance in successful learning environments and a number of characteristics including mentoring, coaching and modeling (encouraging professional growth) have been noted.

Participation can therefore be realized through the kinds of roles members of the community adopt in support of intellectual, social and emotional development over time. In a social networking environment, Preece and Schneiderman's model for social participation seems to be the most appropriate as levels of participation can be modeled through the various roles played by participants.

\subsection{Teacher participation in Online Social Networking Sites}

Thus far, research conducted on teachers' use of SNS and social media has shown some diversity in focus and newer studies such as that of Chen and Bryer have focused on exploring faculty in higher education's use of social media for informal learning [20]. Some studies have even focused on comparing students' and faculty use of social media [21][22][23] and generally reveal non-surprising results that faculty use is significantly less than that of students. A number of barriers to teacher technology change has been noted by researchers[24] and these barriers can be categorized as first-order and second-order to refer to the degree of influence of the environment. There has been some growth in the presence of online teacher 
professional networks such as Global Educators for All and Teachers' Network and spaces such as Twitter, a microblogging social networking site, and LinkedIn, which allows for teacher-specific groups.

Existing literature reveals that there are a number of barriers to teachers adopting new learning environments and methods and a number of constraints related to time, curriculum and administrative demands have been suggested. Hew and Brush found five major reasons for K-12 teachers' participation in selfgenerated online communities, which are sharing emotions, combatting teacher isolation, experiencing a sense of camaraderie, exploring ideas and utilizing the advantages of online environments [25].

This paper focuses on how secondary school teachers in Trinidad and Tobago chose to participate in a specially created SNS and reasons for the levels of participation seen.

\section{Method}

The SNS, TrinbagoTeachersUsingTechnology, was created on a platform called spruz.com and allowed for a number of synchronous and asynchronous Web 2.0 tools such as blogs, wikis, discussion forums, mediasharing, online chats to be embedded. Teachers were invited to participate voluntarily and participants were drawn from those who had expressed an interest in using technology in their classrooms and in exploring emerging technologies. Participants came from all seven geographic districts in Trinidad and there was a fair spread across all curricular areas. A range of ages and teaching experience was also realized.

In this study, data was captured automatically on the website itself as digital talk and digitally created texts. The website is a repository of data reflecting conversations and connections among participants. Artifacts on the website included 'naturally occurring' talk created by participation in activities such as blogs, wikis and forums. Visual images uploaded by participants such as videos, photos and hyperlinks are included. Some of these images were of the participants themselves or of their students while others were not. Moreover, a history of participation was automatically created through postings that provided data on the name of the poster, date posted and the selected Web 2.0 tool. User created profiles, login history, e-mails, participation in online courses as well as opinions on polls were also generated on the site.

Google Analytics tool (www.googleanalytics.com) was used to analyze data on the website. According to the Google website, Google Analytics works by the inclusion of a block of JavaScript code on pages in the website. When visitors to the website view a page, this JavaScript code references a JavaScript file which then executes the tracking operation for Analytics. The tracking operation retrieves data about the page request through various means and sends this information to the Analytics server via a list of parameters attached to a single-pixel image request. This method of crawling the website allowed me to view participation on the site as a whole over time. While the host platform, spruz.com also does this, the range of tools and reports available was not as wide as that of Google.

A focused group of participants were purposefully selected at the end of the study to further interrogate reasons for levels of participation seen. Six participants were interviewed face to face and a number of barriers to participation were suggested.

\section{Results}

According to Google Analytics, 156 different people visited the site over a four-month period. The majority, 93.6\%, came from Trinidad and Tobago and most visitors were repeat visitors $(77 \%)$. Registered users were allowed to post comments and access pages with different tools and activities, while unregistered users could view selected web pages only. Participation varied by choice of Web 2.0 tool, time of the day and location. Participants on the site greatly preferred to view activities facilitated through certain Web 2.0 tools and only a small percentage of them chose to post comments $(7 \%)$. An even smaller percentage of teachers collaborated with myself and other teachers and one person emerged as a leader on the site, through consistent participation and increasingly active role in adding new members. Based on levels of participation on the SNS, a number of different roles of participation have been suggested. These roles are window-shopper, content consumer, content producer, collaborator and leader.

\section{Discussion}

The roles of participation that teachers adopted on this educational SNS have been influenced by Preece and Schneiderman's Reader to Leader framework [18]. Further characterizations by Davies and Merchant have helped to explore roles in terms of site content [1].

I suggest the use of the term window-shoppers to describe visitors to the site who did not register. I believe this term is appropriate as it describes persons who visit the site, spent approximately 12 minutes on the site and viewed about 8 webpages in that time but did not actually enter the site or request registration. I suggest this term instead of the term 'lurkers', which is commonly found in the literature to describe those on the periphery of a community. I prefer to use the term content consumer to describe those who are registered on the site but participated on the site by reading. They did not do much more than set up a user profile. I 
distinguish content producers as those who contributed to the site in writing text, but also used videos, photos hyperlinks, emoticons (in chats) or responded to online polls. Content producers were well evidenced as participants who added content to the site over time and through a number of Web 2.0 tools. Content producers seemed to be satisfied with the site and found it interesting. Collaboration was seen through postings and responses in delayed time and through a series of time logs in real-time activities such as online chats. The role of collaborator was adopted by very few persons and was evidenced by participation in synchronous activities such as chats, wikis and Google docs. In addition, collaboration was described in asynchronous activities such as forum posts where there were a number of exchanges between the original poster and the responder. The role of leader was the most complex to analyze and encompassed a number of other roles such as that of Networker, Risk-taker, Mentor and Encourager. Criteria for satisfying this role were met and a history of participation showed how one teacher acted in all of the roles listed here namely that of reader, contributor and collaborator before emerging as leader.

In order to present a conceptualization of the way participants enacted different roles on the site, I designed the following diagram using a basic Venn diagram tool (see Figure 1). This diagram shows the relative interrelationships among the five roles played by participants based on the occurrences of these roles on the site. I used a set of concentric circles to show the connections among these roles and adapted circles to form ellipses to show the lack of perfection in these relationships. The relative ratios of these circles/ellipses are deliberate to reflect the differences in occurrences of these roles. I have placed windowshoppers on the periphery of the circle of participants as it represents an undetermined number of site visitors, which are on the outside looking in but cannot be classified as participants as they did not register on the site and chose not to place a boundary on it as this role represents an undeterminable number of possible Internet visitors.

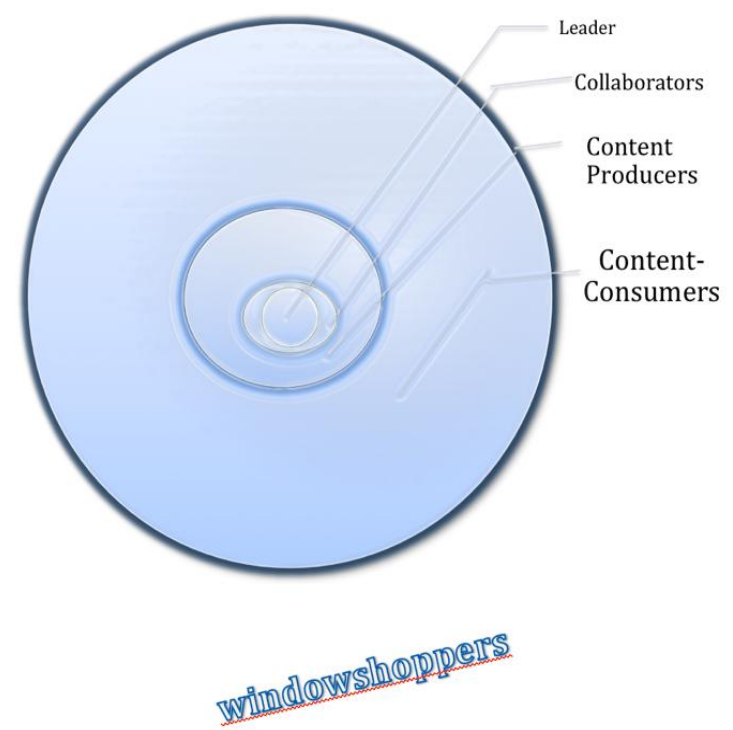

Figure 1. Roles of Participation of Teachers on the educational SNS

\section{Reasons for differences in participation}

In this section, a number of barriers to participation are suggested. It has been noted that the majority of teachers chose to be window-shoppers or content consumers. These barriers include that of time constraints, culture, personal/social, motivational /psychological, mental and technological.

\section{Time Barriers}

In examining reasons for differences in levels of participation on the site, teachers all seemed to indicate that a lack of time/work priorities contributed the most to lower levels of participation. This barrier seems to be supported in the literature [26]. Time is an important factor in understanding site participation on several fronts. Flexibility in time and access to site activities brought control of participation to participants [27] and teachers did exercise this flexibility by accessing the site at all different times of day and night, day of the week and month of the year. In addition, this flexibility allowed teachers to participate in site activities from their homes and other spaces. All online chats, for example, took place at night. On the other hand, time has been identified as a factor affecting teachers' involvement in professional development opportunities [7][28][29]. It seems that a lack of time to engage in social networking activities [30] has affected teachers' levels of participation.

Time is a complex issue in teachers' self-directed learning, as it appears that when teachers do have the 
time to participate, as in the July-August vacation, their levels of participation decreased rather than increased. This indicates that there are other barriers to participation such as personal/social, motivational/psychological, mental, cultural and technological [31][26]. I will illustrate that these barriers did exist for different participants by citing reasons given by participants.

\section{Cultural Barriers}

Barriers related to cultural behavior have been identified as significant in the way knowledge was shared with others. Trinidad teachers have had a history of a top-down approach to professional development. They have not had opportunities to participate in professional development as and when they wish and were usually selected for training instead of opting for it. While teachers have expressed a desire to engage in more democratic forms of professional learning activities, they seemed hesitant to maximize the benefits of this opportunity.

In terms of school culture, teachers in Trinidad and Tobago get two (2) months of paid vacation in a system where teacher professional development is encouraged but not supported, either through fiscal incentives, licensure or mobility. As such, the common view is that teachers are on holidays from school and hence schoolrelated activity. Teachers explain that "this is my time" (Participant A), and this may explain decline in participation during the July-August period of the study. Only two participants (B and C) were active during this period, and this signals differences in teacher professional identity and motivation. My findings did not indicate that teachers made any significant shifts in cultural norms and conventions though the affordances of Web 2.0 tools while collaborating on this SNS, even though this finding was presented in a study on SNS using a Community of Practice perspective [9].

Trinbagonians are also acculturized to looking in at others without actually getting involved themselves. This is locally called 'macoing' or 'minding odder people bizness'. I show an example of a comment that identifies this aspect of our culture.

Participant D: "Well, I think for most trinis, it's the digital form of macoing. Most of us in Trinidad lurk on social websites to look for people they may know or have just met, just to see what they are saying."

The use of the term 'lurk' is familiar to participant D and he sought to explain how he thought most persons on the site participated. The idea of digital 'macoing' seems to accurately describe how and why participants acted in the role as readers. The term 'maco' is a
Trinidad and Tobago word which usually refers to someone who 'minds other peoples business' by spying on the person [32]. The term also refers to 'gossip'. As such 'macoing' is the act of spying or looking at others while they go about their daily lives. While the official language of Trinidad and Tobago is Standard English, the spoken and sometimes written word often incorporates Trinidadian lingo. The use of dialect in this example shows the ease that participants felt in expressing themselves with local language and feeling understood. This supports the need for a website that is localized to Trinidad and Tobago where participants can feel comfortable to use everyday language.

\section{Personal/Social Barriers}

Participants also identified personal/social barriers to participation. Participants $\mathrm{A}, \mathrm{B}$ and $\mathrm{S}$ gave the following reasons for their levels of participation.

A: "It is difficult for me to participate in a strange setting because of my personality. I think that I am an introvert. I also believe that because we were mainly exposed to a teacher centered approach of learning as students, it may be difficult for us to actively participate even now as adults because we are not accustomed to this "new" approach."

B: "It is easy to sit back and watch \& listen to conversation, learning the entire time. Sometimes I (am) unsure of the value of my contribution. Sometimes the conversation seems to be between you and participant Y and I don't want to butt in."

\section{S: "I have found lack of opportunity to participate"}

Reasons for difficulties in participation resulted from resistance to change or due to teacher personality differences. Ottenbreit-Leftwich, Glazewski, Newby and Ertmer suggest that 'teacher beliefs are defined broadly as "tacit, often unconsciously held assumptions about students, classrooms, and the academic material to be taught" and that beliefs have more influence on teacher practice than teacher knowledge [33]. Bai and Ertmer found those teachers' beliefs about teaching and learning might play an important role in the ways in which technology gets used in classrooms [34]. It is important to look at some of these barriers more closely in order to design opportunities for teachers to become effective in the classroom. For teachers to move from their current attitudes to using Web technologies, they need to shift to a more constructivist perspective to teaching, which is claimed as more appropriate for effective technology use [35]. 


\section{${ }^{1}$ Motivational/ Psychological barriers}

Low levels of interest were identified as a factor in levels of participation. The following comment by Participant I seemed to reflect this position.

I: "Low participation in these sessions may also be attributed to a lack of motivation amongst participants"

Maslow's hierarchy of needs is helpful in understanding that participation in online communities is affected by the actor's beliefs and interests [36]. The site TrinbagoTeachersUsingTechnology was created to promote interactions among teachers with special interest in using technology in their classrooms and teachers who volunteered to register on the site indicated that they wanted to 'find colleagues of similar interests'. Yet, when the majority of teachers did not seize given the opportunity to connect with these colleagues,

\section{Mental Barriers}

Participants' comments also indicated that individual differences were significant to online participation. These two comments have indicated differences in how new information is processed and that time was needed to internalize it. These comments may point to communication styles as well differences in cognition.

A: "If the information being shared is new to me, I will not feel comfortable to respond. I need time to think about it".

Y: "I think everyone needs their own time to process information. While it may seem that people are 'lurking', they may be simply turning the material over in their minds until they feel that they want to contribute their thoughts. Same as with many discussions face-to-face. Everyone is different. While you think that these people may somehow be hitch-hiking without contributing, there is no telling what they will provide in their own time later".

Based upon studies on online intercultural communication, Reeder, Macfadyen, Roche, and Chase suggested communicative style (predisposition to participate), participant structure (appropriateness of context) and genre (acceptability of) are conditions for online communication [37]. Critics of social learning theory indicate that the theory does not take into

\footnotetext{
1 Participants" names have been changed to a single letter for anonymity.
}

account individual differences in a social learning environment and there is evidence that even in a socially mediated environment, individuals can learn differently [38].

\section{Technological Barriers}

Another factor indicated by participants was difficulty in using the Web tools on the site. Technological ineptitude [31] [39] and technology barriers [26] have been found in the literature. There have been several instances where the technology itself seemed to have negatively affected teachers' participation. Two examples have been selected to illustrate difficulty with using the technology on the site.

The first example highlights contents of an email with an unregistered participant, after receiving an email invitation from me to join the site.

Subject: Re: RE: You have been invited to join TrinbagoTeachersUsingTechnology

From: xxx@gmail.com

To: yyy@hotmail.com

Hi.

sorry to learn that. I did not know why you were not on even tho $u$ keep saying that $u$ accepted the invite.

Do $u$ have another email that I can use? Vimala

From:yyy@hotmail.com

To: xxx@gmail.com:

$>$ Hi. When I click on the link, I keep receiving the message that the site is blocked.

> Subject: You have been invited to join

TrinbagoTeachersUsingTechnology

> From:xxx@gmail.com

In this email, the invited teacher indicated that the site was blocked and was unable to register. This prevented her from registering at all even though she had accepted an invitation to participate. This may explain as well why other invited teachers may not have been registered as site participants.

In the next example, the contents of a Google chat with participant $X$ are shown to indicate the difficulties she had with Internet access to continue the chat.

8:45 pm me: Chat in 5 mins

9:06 pm me: Hi
misX: Hi gnight
9:07 pm me: How are u?
misX: ok who else will be joining the chat
tonite


9:09 pm me: hang on. Am trying to call you on Google talk

9:10 pm me: are u using a laptop or phone? misX: using a netbook never used Google talk before

9:11 pm me: can u try calling me please?

9:12 pm misX: what do I have to do me: do u see a call button on your google talk by my name?

9:14 pm me: anything yet? misX: I am seeing a telephone symbol and a video symbol

9:15 pm me: $\mathrm{k}$ telephone please

9:17 pm misX: installing the google video and chat but taking a long while

9:18 pm me: do u know your internet speed?

9:19 pm misX:it seems I don't have good connection after $8 \mathrm{pm}$

9:21 pm me:ok go onto the site techtalk.spruz and go to the chatroom and we will see how it goes...

While the chat took some time, most of it was related to technical issues. The chat with her in the chatroom of the techtalk.spruz.com site didn't seem to work either and attempts to work collaboratively failed due in part to poor connectivity

This example shows that even for registered participants, Internet connectivity and navigating the tools on the site were barriers to maximizing participation on the site, even when the participant was willing. Recent media reports indicate that local Internet usage in Trinidad and Tobago is above $50 \%$ but the last official Digital Divide report indicates just $17 \%$ for Internet penetration [40]. Internet access and confidence in using technology tools [41] are significant in teachers' participation.

\section{Implications and Conclusion}

These findings show that the SNS TrinbagoTeachersUsingTechnology allowed teachers in Trinidad and Tobago to participate in in different ways using a variety of asynchronous and synchronous Web 2.0 tools. The combination of these tools afforded site participants opportunities to connect, share and learn from each other, minimally or otherwise. Participation took place across time and space [42] school and curricula area and teachers interacted with those who were previously unknown and distant [43]. Findings indicated that this SNS allowed for social, participatory processes, which were democratic [44] [6] as participants exercised control of their experiences on the SNS and selected activities of their choice in which to participate.

Findings on the site indicated that most teachers participated on the site minimally. I have suggested that teachers adopted five different scaled roles, which are window-shopper, content consumer and producer, collaborator and leader. One teacher participant emerged as a leader on the site, having performed mentoring, and networking roles among others. Teacher leadership has been growing in importance in successful learning environments and this study showcased how leadership was demonstrated on this SNS.

Several barriers to participation have been proposed which are supported in the literature. Several of the barriers to participation echo that of barriers to teacher technology change as described by Bai and Ertmer and Lim and Khine [24][34]. These barriers have been found to be time, personal/social, motivational/ psychological, mental, cultural and technological. I have used these barriers to account for differences in participation levels on the site and the eventual roles played by participants, which I identified as windowshopper, content consumer and producer, collaborator and leader. Ardichvili suggest that some of these barriers can be overcome through development of trust in the environment, a supportive learning culture and the affordances of Web 2.0 tools [31]. These findings allow me to problematize the power of Web 2.0 tools as 'social and participatory' [44], if participants do not feel that their contributions matter or that it is important to contribute to the shared space.

These findings also seem to be consistent with that of Preece and Schneiderman's findings who suggest that while many people participate in online activities by reading, only a fraction will actually contribute by writing in text-based narratives or uploading other digital media forms or including links to other sites or pages [18]. The data has indicated that while participants had the option to contribute content to the site, they generally preferred to simply view existing contents. In online spaces that facilitate knowledgesharing, participation can be categorized as either reading or content consumption and writing or content production [1][19] or even both, which can be encapsulated as content prodsumership. These twin actions represent the more cognitive dimensions of participation, which Selwyn describes together with the social dimension, are directed at learning [27]. Results from this study can offer guidance and direction on how to best utilize educational SNSs to meet the needs of teachers as they engage in daily practice.

There are approximately 17000 teachers in Trinidad and Tobago alone and this localized SNS was focused on providing networking among these teachers. The local design and focus of the website was purposeful in creating a familiar environment for teachers, even though Web 2.0 tools may have been new and it was hoped that teachers would respond more enthusiastically to participation. However, results of 
participation seem to support views of National and Caribbean Technology Business observers who lament about Trinidad and Tobago's (and Jamaica's) declining status in innovation. SiliconCaribe commented "We (Trinbagonians, Jamaicans etc.) seem to be content to be consumers of technology and not creators of technology and the wealth that comes with that" [45]. Findings from this study help to provide a preliminary platform for research on relationships between consumership and production and explore strategies to encourage teachers to become more active contributors and content-creators.

\section{References}

[1] Davies, J. and Merchant, G., "Web 2.0 for Schools: Learning and Social Participation", New York: Peter Lang 2009.

[2] Greenhow, C., Robelia, B. and Hughes, J., "Learning, Teaching and Scholarship in a digital Age: Web 2.0 and Classroom Research: What Path Should We Take Now?",Educational Researcher, 2009, 38(4), pp. 246-259.

[3] Ozkan, B. and McKenzie, B., "Social Networking Tools for Teacher Education", In: K. McFerrin et al., Eds. Proceedings of Society for Information Technology and Teacher Education International Conference, 2008, pp.27722776.

[4] Whitehouse, P., "Networked Teacher Professional Development: The case of Globaloria", Journal of Interactive Learning Research, 2011, 22(1), pp. 139-165.

[5] Darling-Hammond, L., Wei, R. C., Andree, A., Richardson, N. and Orphanos, S., "Professional learning in the learning profession: A status report on teacher development in the United States and abroad", [pdf online], 2009, Available at http://www.srnleads.org/resources/publications/pdf/nsdc_prof dev_short_report.pdf [accessed 14/12/10].

[6] Lieberman, A. and Mace, D., "Making Practice Public: Teacher Learning in the 21st Century", Journal of Teacher Education, Jan/Feb 2010, 61(1-2), pp. 77-88.

[7] Dede, C., Ketelhut,D., Whitehouse,P., Breit,L. and McCloskey,E., "A Research Agenda for Online Teacher Professional Development", Journal of Teacher Education, 2009, 60(8), pp. 8-19.

[8] Desimone, L., "Improving Impact Studies of Teachers' Professional Development: Toward Better Conceptualizations and Methods", Educational Researcher, 2009; 38(3),

ProQuest Psychology Journals, pp. 181-199

[9] Gunawardena, C. N. ,’Social presence theory and implications for interaction and

collaborative learning in computer conferences",

International Journal of Educational

Telecommunications, 1995, 1(2/3), pp. 147-166.
[10] Davies, J. and Graff, M., "Performance in e-learning: online participation and student grades", British Journal of Educational Technology, 2005, 36(4), pp. 657-663

[11] Karam, A. and Dutt Majumder, H., "Time: A Significant Opportunity Cost of Social Networking and Participating in Online Communities of Practice", In: J. Sanchez and K. Zhang, Eds. Proceedings of World Conference on E-Learning in Corporate, Government, Healthcare, and Higher Education, 2010, pp. 2556-2561, Chesapeake, VA: AACE.

[12] Hrastinski, S., "What is online learner participation? A literature review", Computers and Education, 2008, 51(4), pp.1755-1765.

[13] Lave, J., and Wenger, E. Situated learning: Legitimate peripheral participation. 1991. Cambridge, MA: Harvard University Press.

[14] Preece, J., Nonnecke, B., \& Andrews, D., "The top five reasons for lurking: improving community experiences for everyone", Computers in Human Behavior, 2004, 20(2), pp. 201-223.

[15] Tan, V.M., "Examining the Posters and Lurkers: Shyness, Sociability, and Community-related Attributes as Predictors of SNS Participation Online Status", (Master's Thesis). [online], 2008, Available at http://www.com.cuhk.edu.hk/courses/pgp_nm/projects/2011/ Vick Minqi TAM.pdf [Accessed 3/12/11].

[16] de Laat, M., Lally, V. and Lipponen, L. and Simons, R., "Investigating patterns of interaction in networked learning and computer-supported collaborative learning: A role for Social Network Analysis", International Journal of Computer-Supported Collaborative Learning, 2010, 2:1, pp.87-103.

[17] Hrastinski, S., Sjöström, S., Eriksson, J., Larsson, A., and Ozan, H., "Encouraging participation in an intraorganizational online idea community: A case study of a Swedish municipality", First Monday [Online], 2011, 16 (10).

[18] Preece, J. and Schneiderman, B., "The Reader-to-Leader Framework: Motivating Technology-Mediated Social Participation", AIS transactions on human-computer interaction, 2009, pp.1944-3900.

[19] Phang, C. W., Kankanhalli, A. and Sabherwal, R., "Usability and Sociability in Online Communities: A Comparative Study of Knowledge Seeking and Contribution", The Association of Information Systems, 2009, 10(10), pp. 721-747.

[20] Chen,B. and Bryer,T., "Investigating Instructional Strategies for Using Social Media in Formal and Informal Learning", The International Review of Research in Open and Distance Learning, 2012, [online],13 (1). Available from http://www.irrodl.org/index.php/irrodl/article/view/1027/211 5 [accessed 1/3/12] 
[21] Goodman, A., "Student and Faculty uses of Social Networking to Advance Learning in a Higher Education Classroom", In: J. Sanchez and K. Zhang (Eds.), Proceedings of World Conference on E-Learning in Corporate, Government, Healthcare, and Higher Education, 2010, pp. 998-1007

[22] Hew, K.F., "Students and Teachers' Use of Facebook", Computers in Human Behavior, 2011, 27, pp. 662-676.

[23] Roblyer, M., McDaniel, M.,Webb, M., Herman, J. and Witty,J., "Findings on Facebook in higher education: A comparison of college faculty and student uses and perceptions of social networking sites", The Internet and Higher Education, 2010, 13(3),pp: 134-140.

[24] Lim, C.P. and Khine, M.S., "Managing Teachers' Barriers to ICT Integration in Singapore Schools", Journal of Technology and Teacher Education, 2006, 14(1), pp. 97-125.

[25] Hew, K.F. and Brush, T., "Integrating technology into $\mathrm{K}-12$ teaching and learning: current knowledge gaps and recommendations for future research", Education Technology Research and Development, 2007, 55(3),pp.223252.

[26] Hew, K. and Hara, N.,"Empirical study of motivators and barriers of teacher online knowledge sharing",

Educational Technology Research and Development, 2007, 55(6), pp. 573-595.

[27] Selwyn,N., "Education 2.0? Designing the web for teaching and learning: A Commentary by the Technology Enhanced Learning phase of the Teaching and Learning Research Programme", [online], 2008, Available at http://www.eprints.ioe.ac.uk [accessed 3/3/11].

[28] Lawless, K. A., and Pellegrino, J. W., "Professional development in integrating technology into teaching and learning: Knowns, unknowns, and ways to pursue better questions and answers", Review of Educational Research, 2007, 77(4), pp. 575-614.

[29] Ostashewski, N. and Reid, D., "Online Teacher Professional Development: Redesign and Delivery of a Technological Pedagogical Courselet within a Social Networking Site", Proceedings of World Conference on Educational Multimedia, Hypermedia and Telecommunications 2010, pp. 1111-1116,Chesapeake, VA: AACE.

[30] Ray, J., Kalvaitis, D., Wheeler, C. and Hirtle, J. , "Teachers' Attitudes, Behaviors, and Opinions Related to Social Media Use", In: Proceedings of World Conference on E-Learning in Corporate, Government, Healthcare, and Higher Education, 2011, pp. 861-867, Chesapeake, VA: AACE.

[31] Ardichvili, A., "Learning and Knowledge Sharing in Virtual Communities of Practice: Motivators, Barriers, and Enablers", Advances in Developing Human Resources, 2007, 10: 541 .
[32] Mendes, J. 1985. Cote Ci,Cote la: Trinidad and Tobago Dictionary. $2^{\text {nd }}$ ed. Port of Spain: Medianet, p.120.

[33] Ottenbreit-Leftwich, A., Glazewski, K., Newby,T. and Ertmer,P.A., "Teacher value beliefs associated with using technology: Addressing professional and student needs", Computers and Education, 2010, pp.1321-1335.

[34] Bai, H. and Ertmer, P., "Teacher Educators' Beliefs and Technology Uses as Predictors of Preservice Teachers' Beliefs and Technology Attitudes". Journal of Technology and Teacher Education, 2008,16 (1), pp. 93-112.

[35] Palak, D. and Walls, R., "Teachers' Beliefs and Technology Practices: A Mixed-methods Approach", Journal of Research on Teacher Education, 2009, 41(4), pp. 417-441.

[36] Bishop,J., "Increasing participation in online communities: A framework for human-computer interaction", Computers in Human Behavior, 2007, 23, pp: 1881-1893.

[37] Reeder, K., Macfadyen, L.P., Roche, J., and Chase, M., "Negotiating cultures in cyberspace: Participation patterns and problematics", Language Learning and Technology, 2004, 8(2), pp. 88-105.

[38] Salomon, G., \& Perkins, D. N., "Individual and social aspects of learning", Review of research in education, 1998, 23, pp. 1-24.

[39] Cuban, L., Kirkpatrick,H. and Peck,C., "High Access and Low Use of Technologies in High School Classrooms: Explaining an Apparent Paradox. American Educational Research Journal, 2001, 38(4), pp. 813-834.

[40] Ramlal,B. and Watson,P. The Digital divide in Trinidad and Tobago, [online] , 2007. Available at http://www.sta.uwi.edu/conferences/09/salises/.../BRamlal_P Watson\%20.pdf [Accessed 4/3/11]

[41] Bingimlas, K. A., "Barriers to the successful integration of ICT in teaching and learning environments: A review of the literature", Eurasia Journal of Mathematics, Science \& Technology Education, 2009, 5(3), pp. 235-245.

[42] Davies, J., “Affinities and beyond: developing new ways of seeing in online spaces", E-Learning, 2006, 3(2), pp. 21734.

[43] Lee, M. and McLoughlin, C., "Harnessing the affordances of Web 2.0 and social software tools: Can we finally make "student-centered" learning a reality?", World Conference on Educational Multimedia, Hypermedia and Telecommunications (EDMEDIA) 2008, AACE, pp. 38253834

[44] Conole, G., Galley,R. and Culver,J., "Frameworks for Understanding the Nature of Interactions, Networking, and Community in a Social Networking Site for Academic Practice", The International Review of Research in Open and Distance Learning, North America, 2010. [online]. Available from 
$<$ http://www.irrodl.org/index.php/irrodl/article/view/914/166 6> [accessed: 19/3/12].

[45] Riley,I., "Consumers vs creators: Are Jamaicans, Trinidadians and Barbadians happily wasting their time online?" [online]. SiliconCaribe. 2011, Available at http://www.siliconcaribe.com/2011/04/13/consumers-vs-

creators-are-jamaicans-trinidadians-and-barbadians-wastingtheir-time-online/ [Accessed 3/4/2012]. 